Research Article

\title{
Artificial Neural Network Optimization of a Carbon Paste Electrode for the Detection of Zinc lons
}

\author{
Rimal Isaac ${ }^{`}$, Praseetha Prabhakaran \\ Department of Nanotechnology, Noorul Islam Centre for Higher Education, Kumaracoil, Thuckalay, Kanyakumari District, \\ Tamilnadu 629180, India \\ Corresponding author: E-mail: rimalisaac@gmail.com
}

Received:Jan. I, 2016; Accepted: Feb. 18, 2016; Published: Mar. 25, 2016.

Citation: Rimal Isaac and Praseetha Prabhakaran. Artificial Neural Network Optimization of a Carbon Paste Electrode for the Detection of Zinc lons. Nano Biomed. Eng. 2016 8(I), 47-53.

DOI: 10.5101/nbe.v8il.p47-53.

\begin{abstract}
The present work focuses on the fabrication of a potentiometric sensor for the determination of zinc ions using 3,7,12,17-Tetramethyl-8,13-divinyl-2,18-porphinedipropionic acid disodium salt (protoporphyrin IX disodium) as the ionophore. The electrode is fabricated by various composition of protoporphyrin IX disodium, graphite, multiwalled carbon nanotube, paraffin oil, and sodium tetraphenyl borate. These factors are varied at 5 levels. The composition of the electrode is optimized using artificial neural network. The optimization of electrode composition was carried out using genetic algorithm, rotation inherit optimization and particle swarm optimization techniques. The genetic algorithm (GA) optimized electrode was prepared with the composition ionophore $(9.71 \mathrm{mg})$, paraffin oil (drop) (7.17), NaTPB (5.31 mg), graphite $(244.82 \mathrm{mg}$ ) and MWCNT (21.82 $\mathrm{mg}$ ) showed better response with a a Nernstian slope of $29.69 \mathrm{mV} / \mathrm{decade}$. It also showed a linear response in the concentration range of $1.0 \times 10^{-1} \mathrm{M}$ to $3.09 \times 10^{-7} \mathrm{M}$ and a detection limit of $1.9 \times 10^{-7} \mathrm{M}$. The electrode showed a good selectivity for $\mathrm{Zn}^{2+}$ relative to many studied cations. The GA optimized electrodes showed a stable response in the $\mathrm{pH}$ range of 2.7 to $7.0 \mathrm{w}$ with a response time less than $20 \mathrm{~s}$ for all the tested concentration ranges. Analytical application of the electrode was demonstrated by using the prepared electrode as an indicator electrode for the potentiometric titration of $\mathrm{Zn}^{2+}$ against EDTA.
\end{abstract}

Keywords: Ion-Selective Electrodes; Neural Networks; Carbon Nanotubes; Optimization; Biosensor

\section{Introduction}

Ion-selective electrode (ISE) is a potentiometric sensor whose potential indicates the activity of the target ion [1]. Carbon based ISEs electrodes possess advantages like inertness, low cost, low background current and applicability for wide range of analysis [2]. There are many carbon electrodes available out of these glassy carbon and carbon paste electrode (CPE) are the widely used [3-8]. CPEs are made by using graphite and paraffin oil. The paraffin oil employed serves as nonelectrolytic binder. To this carbon paste the ion selective material, ionophore is added. This makes the electrode selective to a particular ion of interest.

Modification of these electrodes with nanomaterials are of great interest because of their unique properties $[3,5,9,10]$. The added nanomaterials can act as conducting centers thereby promoting electron transfer [11]. These electrodes are widely used for clinical 
monitoring and environmental analysis. Zinc is a metal which is having numerous applications in paints, alloys and oxides of zinc are used in cosmetics. This metal is also essential for living organisms for the normal metabolism to take place [12]. Excess levels of zinc in the body can cause nausea, vomiting, pulmonary manifestation and gastroenteritis [13].

In view of these toxic effects it becomes necessary to detect the amount of zinc. Large number of works are reported in the development of ISEs for zinc determination [14-18]. In this present work a novel ISE is developed using CPE with multi-walled carbon nanotube (MWCNT), graphite, protoporphyrin IX disodium salt as the ionophore, sodium tetraphenylborate (NaTPB) as the additive and paraffin oil as the binder (Fig. 1). The components of the ISE is optimized using artificial neural network (ANN).

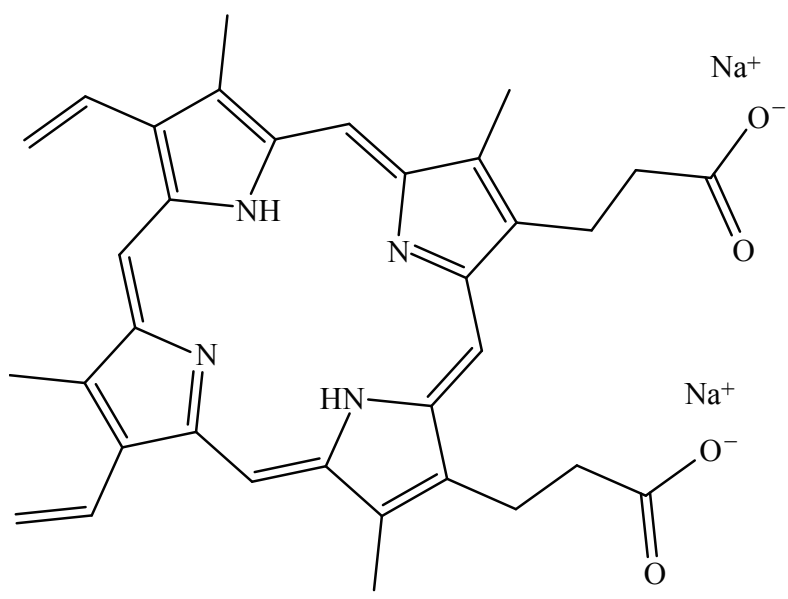

Fig. 1 Structure of Protoporphyrin IX disodium salt $(3,7,12$, 17-Tetramethyl-8,13-divinyl-2,18-porphinedipropionic acid disodium salt).

\section{Materials and Methods}

\section{Chemicals and Instruments}

All the chemicals used were of analytical grade and used as such. Ultra-pure water is used for all the experiments (Milli-Q System; Millipore Corp). The chemicals were purchase from Merck, Mumbai (Graphite, sodium hydroxide and paraffin oil); United Nanotech Innovations Pvt. Ltd., Bangalore, India (MWCNT); Sigma Aldrich (Protoporphyrin IX disodium salt and Zinc chloride); Spectrum chemicals, Cochin (Potassium chloride, manganous chloride and barium chloride); Himedia, Mumbai (Ammonium chloride, copper(II) chloride, Ethylenediaminetetraacetic acid disodium salt and NaTPB); Loba chemie Pvt Ltd, Mumbai (Sodium chloride and silver chloride); NICE chemicals, Kochi (Ferrous chloride and hydrochloric acid); Thomas Baker chemicals private Ltd, Mumbai (Stannous chloride and cobalt chloride); High Purity Laboratory Chemicals Pvt. Ltd. (Tetrahydrofuran (THF)). A homemade potentiometer is used for the potential measurement [19]. The potential measurements were done by using the following assembly:

$$
\mathrm{Ag} \mid \mathrm{AgCl}, \mathrm{KCl} \text { (satd.) || test solution }|\mathrm{CPE}| \mathrm{Cu}
$$

All the measurements were carried out at room temperature against $\mathrm{Ag} \mid \mathrm{AgCl}$ reference electrode.

\section{Electrode Fabrication}

The materials graphite, ionophore, NaTPB and MWCNT of different compositions (Table 1) were mixed in 7-10 mL THF in a $25 \mathrm{~mL}$ beaker. The mixture was mixed several times by sonication and by using a spatula for $15 \mathrm{~min}$. The mixing was repeated several times to get a homogenous mixture. After mixing, the THF was allowed to evaporate completely at room temperature. Now to the above mixture the required quantity of paraffin oil was added and hand mixed in an agate mortar and pestle to form a homogenous paste. This carbon paste prepared (CP) was packed into the electrode body.

The electrode body used was a polyethylene syringe ( $4 \mathrm{~mm}$ i.d., $1 \mathrm{ml}$ ), the tip was cut off with a blade. The filling of the electrode body was done in small portions by pressing the $\mathrm{CP}$ completely into the body before filling with the next portion. The electrode surface was polished against a white paper to obtain a smooth and shiny surface. The advantage of this electrode is it does not require internal filling solution. The surface of the electrode is renewed before each set of experiments, this was done by pushing the contents of the electrode from the end opposite to the smooth surface and removing a little of the $\mathrm{CP}$ from the smooth surface end and the electrode is polished as mentioned previously. The electrode was used as such without any modifications. For electrical contact, a copper wire was used which was pushed in to the other end of the electrode away from the smooth surface.

\section{Selectivity Coefficient Determination}

Selectivity of the electrode is determined by using fixed interference method. In this method the activity of the interfering ion $\left(a_{B}=1.0 \times 10^{-2} \mathrm{M}\right)$ is kept constant and the activity of the primary ion $\left(a_{A}\right)$ is varied. The 
emf values obtained are plotted vs the logarithm of the activity of the primary ion without the interfering ion as well as the logarithm of the activity of the primary ion in the presence of the interfering ion. The intersection of the extrapolated linear segments of the graph gives the value of $a_{A}$. The selectivity coefficient is measured using the following equation:

$$
K_{A, B}^{p o t}=\frac{a_{A}}{\left(a_{B}\right)^{\frac{z_{A}}{z_{B}}}}
$$

$z_{A}$ and $z_{B}$ are the charges of the primary and interfering ion.

\section{Artificial Neural Network Modeling}

NeuralPower (version 2.5, CPC-X Software, USA) a powerful ANN package is used for the modeling. Multilayer normal feed forward is used for the training process. The response of the electrode is measured as the slope of the calibration graph. The network was trained by using different training algorithms namely incremental back propagation (IBP), batch back propagation (BBP) and quickprob (QP). The number of hidden neurons and the best algorithm was chosen by trial and error. The chosen algorithm was trained until it reached a root mean square error (RMSE) value of 0.01 . Other ANN parameters were chosen as the default values. The experimental data is divided into training and testing sets as shown in Table 1. The experimental values of the predicted optimal composition is used as the validation set. The capabilities of the technique is compared with the experimental values by measuring the absolute average deviation (AAD), coefficient of determination (DC), and networks' correlation coefficient (R) using the following equations:

$$
\begin{aligned}
& \mathrm{AAD}=\left\{\left[\sum_{i=1}^{n}\left(\frac{\left|\mathrm{Y}_{\text {exp }}^{\mathrm{i}}-\mathrm{Y}_{\mathrm{pre}}^{\mathrm{i}}\right|}{\mathrm{Y}_{\exp }^{\mathrm{i}}}\right)\right] / n\right\} \times 100 \\
& \mathrm{DC}=1-\frac{\sum_{i=1}^{n}\left(\mathrm{Y}_{\exp }^{\mathrm{i}}-\mathrm{Y}_{\mathrm{pre}}^{\mathrm{i}}\right)^{2}}{\sum_{i=1}^{n}\left(\mathrm{Y}_{\exp }^{\mathrm{i}}-\bar{Y}\right)^{2}} \\
& \mathrm{R}=\frac{\sum_{i=1}^{n}\left(\mathrm{Y}_{\exp }^{\mathrm{i}}-\bar{Y}\right)\left(\mathrm{Y}_{\mathrm{pre}}^{\mathrm{i}}-\overline{Y_{p r e}}\right)}{\sqrt{\sum_{i=1}^{n}\left(\mathrm{Y}_{\exp }^{\mathrm{i}}-\bar{Y}\right)^{2}} \sqrt{\sum_{i=1}^{n}\left(\mathrm{Y}_{\mathrm{pre}}^{\mathrm{i}}-\overline{Y_{p r e}}\right)^{2}}}
\end{aligned}
$$

where $\mathrm{Y}_{\text {exp }}^{\mathrm{i}}$ and $\mathrm{Y}_{\text {pre }}^{\mathrm{i}}$ are the experimental and the predicted response, $\bar{Y}$ is the average of the experimental values, is the average of the predicted values, $\overline{Y_{p r e}}$ and $n$ is the number of experimental data.

\section{Result and Discussion}

The suggested neural network model for the present study is shown in Fig. 2. Tanh is used as the transfer function for both hidden and output layers. The best ANN model and the training algorithm is chosen based on the model with the lowest RMSE value (Table 2). The coefficient of determination $\left(\mathrm{R}^{2}\right.$ or $\mathrm{DC}$ ) values were used to compare the different models. A model is considered to be accurate when the DC value is close to 1.0. From the obtained results, the model with the lowest RMSE (0.0002035) value and the highest R (1.0) and DC (1.0) values was chosen as the best model. BBP algorithm with 7 hidden neurons is chosen as the best model to train the algorithm.

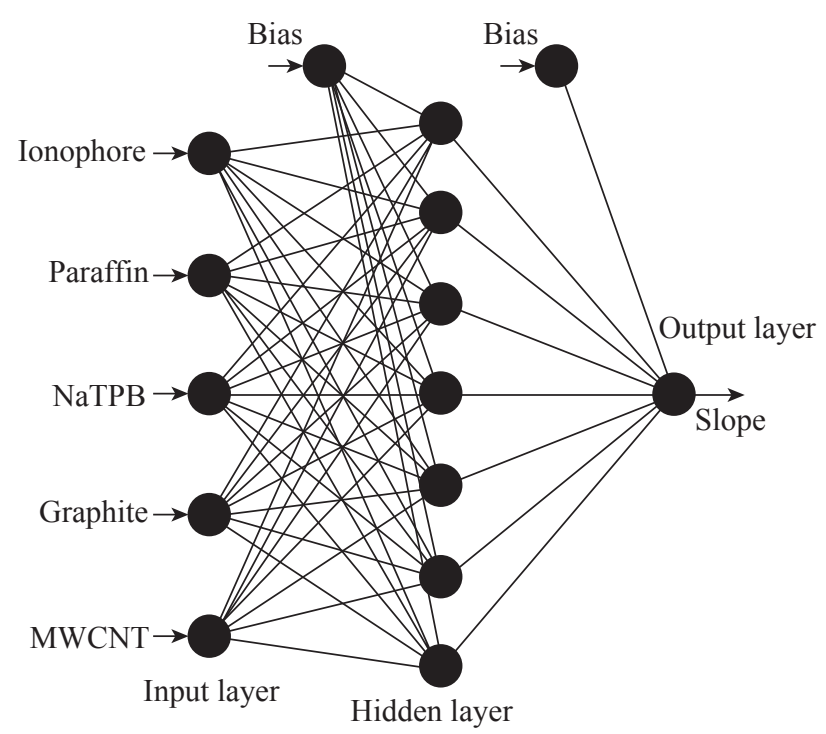

Fig. 2 Structure of the neural network model used for the optimization of electrode composition.

From the results, the AAD values for the training and test data were found to be $0.016 \%$ and $0.026 \%$. The DC value was obtained as 0.9999 for both training and test data sets. RMSE value of 0.00562 and 0.00935 was obtained for both training and test data's. An R value of 1.0 and 0.9999 was obtained for training and test data. From the results it is clear that the comparison of predicted and experimental values in training and testing data sets shows that ANN is capable of predicting both known and unknown response. It also shows that models can be obtained from ANN which can be used to show the relationship between the input factors and the response of the sensor.

The optimization was carried out using genetic algorithm (GA), rotation inherit optimization (RIO) and particle swarm optimization (PSO) techniques present in the NeuralPower software. The results of the optimization is shown in Table 3. The composition of 
Table 1 Experimental design in ANN study showing the observed and the predicted response

\begin{tabular}{|c|c|c|c|c|c|c|c|}
\hline \multirow[b]{3}{*}{ Ionophore (mg) } & \multirow[b]{3}{*}{ Paraffin Oil (drop) } & \multirow{2}{*}{\multicolumn{2}{|c|}{ Factors }} & \multirow[b]{3}{*}{ MWCNT (mg) } & \multicolumn{3}{|c|}{ Response } \\
\hline & & & & & \multicolumn{3}{|c|}{ Slope (mV) } \\
\hline & & NaTPB (mg) & Graphite (mg) & & Observed & Predicted & Difference \\
\hline 4 & 3 & 2 & 250 & 10 & 13.88 & 13.87 & 0.01 \\
\hline 8 & 7 & 6 & 250 & 20 & 16.33 & 16.33 & 0.00 \\
\hline 8 & 3 & 2 & 150 & 10 & 22.45 & 22.46 & -0.01 \\
\hline 4 & 7 & 2 & 250 & 20 & 39.42 & 39.42 & 0.00 \\
\hline 4 & 7 & 6 & 150 & 20 & 41.22 & 41.22 & 0.00 \\
\hline 8 & 7 & 6 & 150 & 10 & 45.12 & 45.12 & 0.00 \\
\hline 6 & 5 & 4 & 200 & 15 & 27.12 & 27.13 & -0.01 \\
\hline 4 & 3 & 2 & 150 & 20 & 8.55 & 8.56 & -0.01 \\
\hline 4 & 3 & 6 & 150 & 10 & 22.45 & 22.45 & 0.00 \\
\hline 8 & 3 & 6 & 150 & 20 & 33.44 & 33.44 & 0.00 \\
\hline 8 & 7 & 2 & 250 & 10 & 45.74 & 45.75 & -0.01 \\
\hline 4 & 7 & 2 & 150 & 10 & 16.22 & 16.22 & 0.00 \\
\hline 8 & 3 & 6 & 250 & 10 & 46.2 & 46.20 & 0.00 \\
\hline 8 & 7 & 2 & 150 & 20 & 19.25 & 19.26 & -0.01 \\
\hline 4 & 7 & 6 & 250 & 10 & 42.15 & 42.15 & 0.00 \\
\hline 4 & 3 & 6 & 250 & 20 & 14.56 & 14.56 & 0.00 \\
\hline 8 & 3 & 2 & 250 & 20 & 49.7 & 49.71 & -0.01 \\
\hline 2 & 5 & 4 & 200 & 15 & 34.85 & 34.85 & 0.00 \\
\hline 6 & 5 & 4 & 100 & 15 & 24.45 & 24.44 & 0.01 \\
\hline 6 & 5 & 4 & 200 & 25 & 22.18 & 22.18 & 0.00 \\
\hline 6 & 1 & 4 & 200 & 15 & 14.45 & 14.45 & 0.00 \\
\hline 10 & 5 & 4 & 200 & 15 & 55.23 & 55.15 & 0.08 \\
\hline 6 & 9 & 4 & 200 & 15 & 31.55 & 31.55 & 0.00 \\
\hline 6 & 5 & 4 & 300 & 15 & 37.57 & 37.57 & 0.00 \\
\hline 6 & 5 & 8 & 200 & 15 & 25.32 & 25.32 & 0.00 \\
\hline 6 & 5 & 0 & 200 & 15 & 10.45 & 10.40 & 0.05 \\
\hline 6 & 5 & 4 & 200 & 5 & 31.29 & 31.29 & 0.00 \\
\hline
\end{tabular}

ANN training set: normal and italic

ANN testing set: bold numbers

the electrode is optimized so that the calibration curve has a response slope of $29.55 \mathrm{mV} /$ decade.

The response of the electrode was measured in a concentration range of $1.0 \times 10^{-1} \mathrm{M}$ to $1.0 \times 10^{-8} \mathrm{M}$ zinc ion. As shown in Fig. 3, the response of the electrode optimized using GA gave good response with a Nernstian slope of $29.69 \mathrm{mV} /$ decade. It showed a linear response in the concentration range of $1.0 \times 10^{-1}$ $\mathrm{M}$ to $3.09 \times 10^{-7} \mathrm{M}$ and a detection limit of $1.9 \times 10^{-7} \mathrm{M}$. The effect of $\mathrm{pH}$ on the optimized electrode is studied at a fixed zinc concentration $\left(1.0 \times 10^{-3} \mathrm{M}\right)$ in different $\mathrm{pH}$ solutions (Fig. 4). The electrode showed a linear response in the $\mathrm{pH}$ range of 2.7 to 7.0.

The importance of the different factors on the 
Table 2 RMSE values obtained for different training algorithms

\begin{tabular}{cccc}
\hline \multirow{3}{*}{ Model } & \multicolumn{3}{c}{ RMSE } \\
\cline { 2 - 4 } & IBP & BBP & QP \\
\hline $5-1-1$ & 10.087 & 11.771 & 10.088 \\
$5-2-1$ & 6.9054 & 8.573 & 7.3777 \\
$5-3-1$ & 2.5724 & 2.8846 & 3.5193 \\
$5-4-1$ & 1.381 & 0.43112 & 2.0203 \\
$5-5-1$ & 0.57303 & 0.043977 & 0.92199 \\
$5-6-1$ & 0.30591 & 0.033163 & 0.37079 \\
$5-7-1$ & 0.17398 & 0.000204 & 0.43255 \\
$5-8-1$ & 0.50017 & 0.016404 & 0.26386 \\
$5-9-1$ & 0.10697 & 0.038935 & 0.50613 \\
$5-10-1$ & 0.22765 & 0.000634 & 0.39083 \\
\hline
\end{tabular}

Table 3 Optimum composition and the response slope for the electrodes obtained by the different optimization techniques

\begin{tabular}{cccc}
\hline & GA & RIO & PSO \\
\hline Ionophore (mg) & 9.71 & 8.99 & 9.01 \\
Paraffin Oil (drop) & 7.17 & 6.40 & 7.66 \\
NaTPB (mg) & 5.31 & 5.03 & 1.90 \\
Graphite (mg) & 244.82 & 204.89 & 192.87 \\
MWCNT (mg) & 21.82 & 22.40 & 20.00 \\
Slope (mV/decade) & 29.69 & 27.47 & 30.48 \\
\hline
\end{tabular}

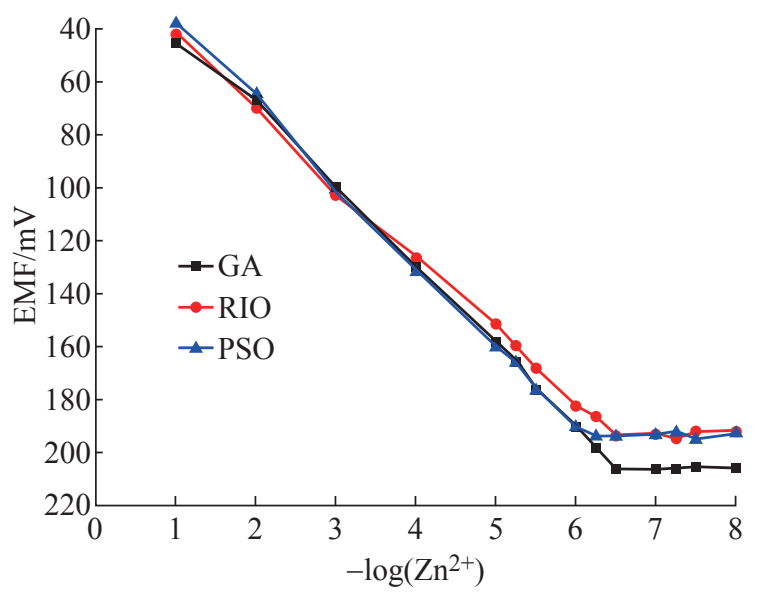

Fig. 3 Calibration curve for the different electrode optimized by GA, RIO and PSO techniques.

response is evaluated using the ANN model and is given by the sensitivity analysis. The results of the sensitivity analysis is presented in Fig. 5. From the results, ionophore $(22.74 \%)$ has the highest contribution towards the response of the electrode than all the other factors under investigation.

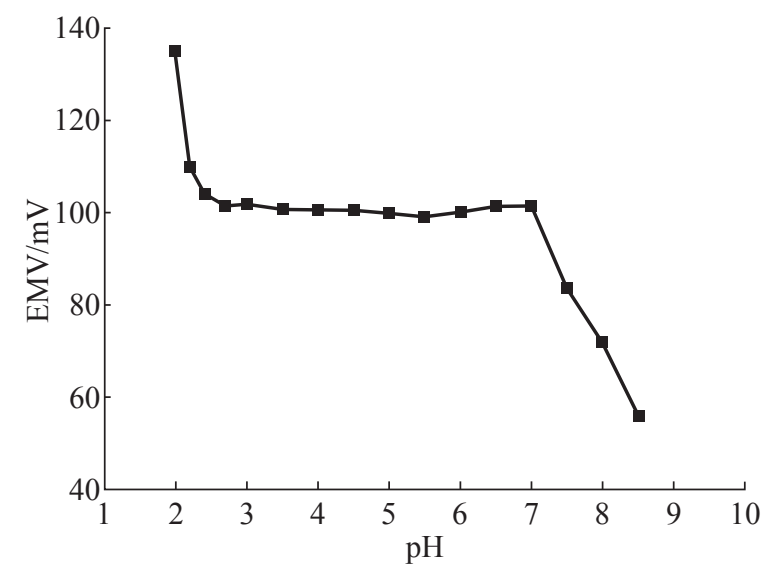

Fig. 4 Response of the GA optimized electrode towards solutions of different $\mathrm{pH}$.

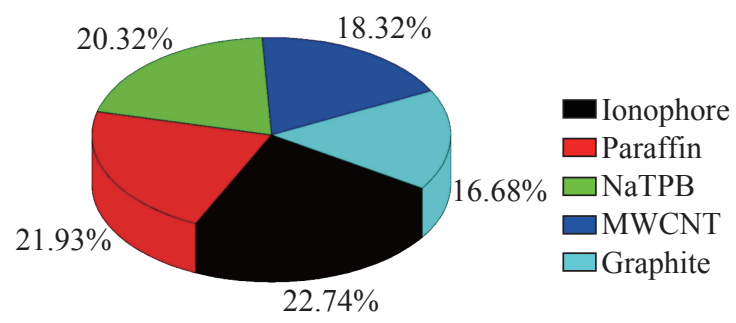

Fig. 5 Importance of the different factors analyzed by ANN model.

By fixed interference technique the selectivity coefficient of the electrode optimized using GA is studied and given in Table 4. By examining the selectivity coefficient, the electrode has less selectivity towards the tested ions. This shows that there will be less interference from these ions during the measurement of zinc ion.

The reproducibility of GA optimized electrode is

Table 4 Potentiometric selectivity coefficient determined using fixed interference method $\left(a_{B}=1.0 \times 10^{-2} \mathrm{M}, z_{A}\right.$ and $z_{B}$ are the charges of the primary ion (ie., $\mathrm{Zn}^{2+}, z_{A}=2$ ) and interfering ion $\left(\mathrm{ex}\right.$ : for $\left.\mathrm{Co}^{2+}, z_{B}=2\right)$

\begin{tabular}{ccc}
\hline Interfering ions (B) & $a_{A}$ & Selectivity coefficient \\
\hline $\mathrm{Co}^{2+}$ & $4.2 \times 10^{-4}$ & $4.2 \times 10^{-2}$ \\
$\mathrm{Fe}^{2+}$ & $2.3 \times 10^{-6}$ & $2.3 \times 10^{-4}$ \\
$\mathrm{Cu}^{2+}$ & $5.7 \times 10^{-4}$ & $5.7 \times 10^{-2}$ \\
$\mathrm{Sn}^{2+}$ & $9.2 \times 10^{-5}$ & $9.2 \times 10^{-3}$ \\
$\mathrm{Na}^{+}$ & $9.8 \times 10^{-6}$ & $9.8 \times 10^{-2}$ \\
$\mathrm{~K}^{+}$ & $1.3 \times 10^{-6}$ & $1.3 \times 10^{-2}$ \\
$\mathrm{Ag}^{+}$ & $3.8 \times 10^{-6}$ & $3.8 \times 10^{-2}$ \\
$\mathrm{Mn}^{2+}$ & $7.4 \times 10^{-6}$ & $7.4 \times 10^{-4}$ \\
$\mathrm{Ba}^{2+}$ & $5.2 \times 10^{-5}$ & $5.2 \times 10^{-3}$ \\
$\mathrm{NH}^{4+}$ & $2.1 \times 10^{-3}$ & $2.1 \times 10^{-2}$ \\
\hline
\end{tabular}


Table 5 The reproducibility of the electrode response of GA optimized electrode

\begin{tabular}{cccc}
\hline Electrode & Slope $^{\mathrm{a}}$ & $\begin{array}{c}\text { Correlation } \\
\text { coefficient }\end{array}$ & Linear Range $^{\mathrm{b}}$ \\
\hline 1 & 29.69 & 0.999 & $0.1-0.31$ \\
2 & 29.03 & 0.997 & $0.1-0.31$ \\
3 & 29.25 & 0.997 & $0.1-0.31$ \\
4 & 29.42 & 0.999 & $0.1-0.31$ \\
5 & 28.95 & 0.998 & $0.1-0.31$ \\
$\mathrm{RSD}= \pm 0.29$ & $\begin{array}{c}\text { Average } \\
\text { slope }=29.26\end{array}$ & Average $=0.998$ & \\
\hline
\end{tabular}

${ }^{a} \mathrm{mV} /$ decade concentration

${ }^{b}$ Linear range $(\mathrm{M}-\mu \mathrm{M})$

shown in Table 5. The average of the calculated slope for the 5 electrode prepared with the composition optimized by GA was found to be $29.26 \pm 0.29 \mathrm{mV} /$ decade, which shows that the electrode response is highly reproducible. The potentiometric response of the electrode was checked for a period of 4 weeks in different concentrations of $\mathrm{Zn}^{2+}$ and the same was repeated every day. During this period the response of the electrode was found to be unaltered. Beyond this period of time there was slight change in the response of the electrode showing that the electrode cannot be used beyond a period of 4 weeks. The electrode showed a response time of $20 \mathrm{~s}$.

The practical application of the $\mathrm{Zn}^{2+}$ ISE optimized by GA was demonstrated by using the prepared electrode as an indicator electrode for the potentiometric titration of $\mathrm{Zn}^{2+}$ against EDTA. The potentiometric titration was performed by titrating

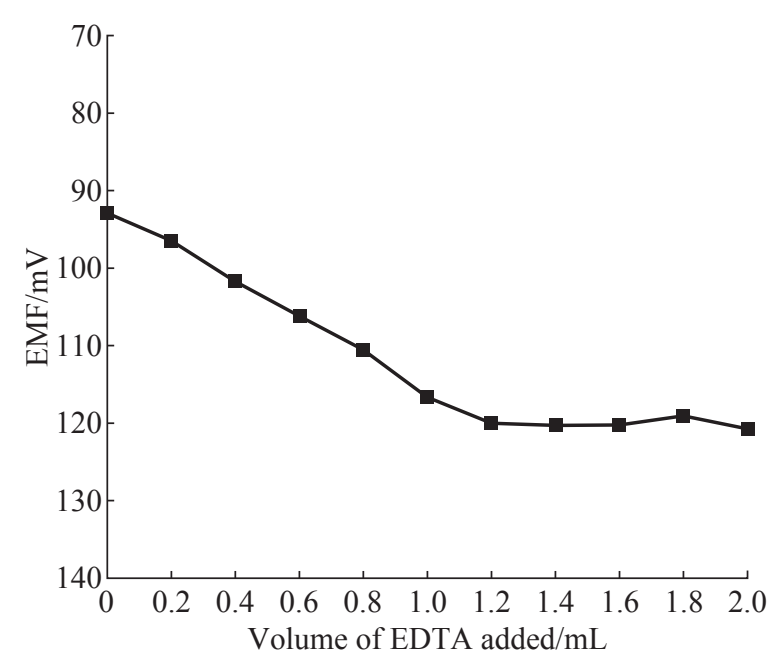

Fig. 6 Potentiometric titration curve for $\mathrm{Zn}^{2+}\left(1.0 \times 10^{-3} \mathrm{M}, 10\right.$ $\mathrm{mL})$ against EDTA $\left(1.0 \times 10^{-2} \mathrm{M}\right)$ using the electrode fabricated with the composition optimized by GA as an indicator electrode.
$1.0 \times 10^{-3} \mathrm{M} \mathrm{Zn}^{2+}$ solution against $1.0 \times 10^{-2} \mathrm{M}$ EDTA solution. The results of the potentiometric titration is shown in Fig. 6. The sharp breakpoint in the graph corresponds to the potentiometric determination of $\mathrm{Zn}^{2+}$.

\section{Conclusion}

To the best of author's knowledge, this is the first time optimization of a $\mathrm{Zn}^{2+}$ CP ISE using ANN is carried out incorporating a nanomaterial is developed. The effects of the different sensor components namely, ionophore, NaTPB, MWCNT, paraffin oil and graphite on the response of the electrode (slope) was studied and the composition of the different components were optimized using ANN. The GA optimized electrode showed a better response of $29.26 \pm 0.29 \mathrm{mV}$ decade $^{-1}$ and a detection range of $0.1 \mathrm{M}$ to $0.31 \mu \mathrm{M}$. The detection limit of the electrode optimized by GA was found to be $1.9 \times 10^{-7} \mathrm{M}$. By examining the selectivity coefficient, the optimized electrode can be used for the detection of $\mathrm{Zn}^{2+}$ with good selectivity in the presence of $\mathrm{Co}^{2+}, \mathrm{Fe}^{2+}, \mathrm{Cu}^{2+}, \mathrm{Sn}^{2+}, \mathrm{K}+, \mathrm{Ag}^{+}, \mathrm{Mn}^{2+}, \mathrm{Ba}^{2+}, \mathrm{NH}^{4+}$ and $\mathrm{Na}^{+}$. The GA optimized electrode worked well over a $\mathrm{pH}$ range of 2.7 to 7.0. The response time of the electrode was found to be $20 \mathrm{~s}$. The life time of the electrode was studied by checking electrode response was checked for a period of 4 weeks. Over these period the response was obtained without any considerable change. Analytical application was performed by using the prepared electrode as an indicator electrode for the potentiometric titration of $\mathrm{Zn}^{2+}$ against EDTA.

\section{Acknowledgement}

The authors are highly thankful to Dr. A. P. Majeed Khan, Chairman of Noorul Islam Centre for higher Education for providing with the facilities to undertake the work.

\section{References}

[1] J. Koryta, Ion-selective electrodes, Annu. Rev. Mater. Sci., 1986, 16: 13-27.

[2] N. Maleki, A. Safavi, F. Tajabadi, High-performance carbon composite electrode based on an ionic liquid as a binder, Anal. Chem., 2006, 78: 3820-3826.

[3] H. Beitollahi, H. Karimi-Maleh, H. Khabazzadeh, Nanomolar and selective determination of epinephrine in the presence of norepinephrine using carbon paste electrode modified with carbon nanotubes and novel 2-(4-Oxo-3-phenyl-3,4-dihydro-quinazolinyl)-N'-phenyl- 
hydrazinecarbothioamide, Anal. Chem., 2008, 80: 98489851.

[4] M. Elyasi, M. A. Khalilzadeh, H. Karimi-Maleh, High sensitive voltammetric sensor based on Pt/CNTs nanocomposite modified ionic liquid carbon paste electrode for determination of Sudan I in food samples, Food Chem., 2013, 141: 4311-4317.

[5] H. Karimi-Maleh, P. Biparva, M. Hatami, A novel modified carbon paste electrode based on $\mathrm{NiO} / \mathrm{CNTs}$ nanocomposite and (9,10-dihydro-9,10-ethanoanthracene11,12-dicarboximido)-4-ethylbenzene-1,2-diol as a mediator for simultaneous determination of cysteamine, nicotinamide adenine dinucleotide and folic acid, Biosens. Bioelectron., 2013, 48: 270-275.

[6] I. Noviandri, R. Rakhmana, Carbon paste electrode modified with carbon nanotubes and poly (3-aminophenol) for voltammetric determination of paracetamol, Int. J. Electrochem. Sci., 2012, 7: 4479-4487.

[7] M.M. Rahman, S.B. Khan, G. Gruner, et al., Chloride ion sensors based on low-dimensional $\alpha-\mathrm{MnO} 2-\mathrm{Co} 3 \mathrm{O} 4$ nanoparticles fabricated glassy carbon electrodes by simple I-V technique, Electrochim. Acta, 2013, 103: 143150.

[8] H.R. Rajabi, M. Roushani, M. Shamsipur, Development of a highly selective voltammetric sensor for nanomolar detection of mercury ions using glassy carbon electrode modified with a novel ion imprinted polymeric nanobeads and multi-wall carbon nanotubes, J. Electroanal. Chem., 2013, 693: 16-22.

[9] M. A. Abbasi, Z.H. Ibupoto, M. Hussain, et al., Potentiometric zinc ion sensor based on honeycomb-like NiO nanostructures, Sensors, 2012, 12: 15424-15437.

[10] C.R.T. Tarley, V.S. Santos, B.E.L. Baêta, et al., Simultaneous determination of zinc, cadmium and lead in environmental water samples by potentiometric stripping analysis (PSA) using multiwalled carbon nanotube electrode, J. Hazard. Mater., 2009, 169: 256-262.

[11] M. Mazloum-Ardakani, M.A. Sheikh-Mohseni, H. Beitollahi, et al., Electrochemical determination of vitamin $\mathrm{C}$ in the presence of uric acid by a novel $\mathrm{TiO} 2$ nanoparticles modified carbon paste electrode, Chin. Chem. Lett., 2010, 21: 1471-1474.

[12] J.C. King, Zinc: an essential but elusive nutrient, $A m$. J. Clin. Nutr., 2011, 94: 679S-684S.

[13] G.J. Fosmire, Zinc toxicity, Am. J. Clin. Nutr., 1990, 51: 225-227.

[14] S. Chandra, D.R. Singh, Zinc (II) selective poly (vinyl chloride) membrane ISE using a macrocyclic compound 1,12,14-triaza-5,8-dioxo-3 (4),9 (10)-dibenzoylcyclopentadeca-1,12,14-triene as neutral carrier, J. Saudi Chem. Soc., 2010, 14: 55-60.

[15] M. Hosseini, S.D. Abkenar, M. Ganjali, et al., Determination of zinc (II) ions in waste water samples by a novel zinc sensor based on a new synthesized Schiff's base, Mater. Sci. Eng., C, 2011, 31: 428-433.

[16] M.A. Akl, M.H.A. El-Aziz, Polyvinyl chloride-based 18-crown-6, dibenzo18-crown-6 and calix-[6]-arene zinc (II)-potentiometric sensors, Arabian J. Chem., 2011, Accepted Manuscript.

[17] F. Mizani, M. Ziaeiha, Design and Construction of High-Sensitive and Selective Zinc (II) Electrochemical Membrane Sensor Based on N, N-bis (2hydroxy-4metoxybenzaldehyde)-2, 6-di amino pyridine, Int. J. Electrochem. Sci., 2012, 7: 7770-7783.

[18] I.M. Isa, S.M. Noor, Y. Juahir, et al., Zinc (II) Selective Electrode based on Polymeric Membrane of 2, 6-Diacetylpyridinebis (benzenesulfonylhydrazide) Ligand, Int. J. Electrochem. Sci., 2014, 9: 4512-4522.

[19] R.T. da Rocha, I.G. Gutz, C.L. do Lago, From christmas ornament to glass electrode, J. Chem. Educ., 1995, 72: $1135-1136$.

Copyright $\subset 2016$ Rimal Isaac and Praseetha Prabhakaran. This is an open-access article distributed under the terms of the Creative Commons Attribution License, which permits unrestricted use, distribution, and reproduction in any medium, provided the original author and source are credited. 